\title{
Spontaneous childbirth-related mental images among pregnant women: A mixed- method study
}

Céline Favrod, M.Sc. ${ }^{1}$, Emily A. Holmes, Ph.D. ${ }^{2}$,Yvan Vial, MD ${ }^{1}$, Mathilde Morisod Harari, $\mathrm{MD}^{3} \&$ Antje Horsch, D.Clin.Psych. ${ }^{1,4^{*}}$

${ }^{1}$ Department Woman-Mother-Child, Lausanne University Hospital, Lausanne, Switzerland

${ }^{2}$ Division of Psychology, Department of Clinical Neuroscience, Karolinska Institutet, Stockholm, Sweden

${ }^{3}$ Department of Child and Adolescent Psychiatry, Lausanne University Hospital, Lausanne, Switzerland

${ }^{4}$ Institute of Higher Education and Research in Healthcare, University of Lausanne and Lausanne University Hospital, Lausanne, Switzerland

${ }^{*}$ Corresponding author: Prof. Antje Horsch, Institute of Higher Education and Research in Healthcare, University of Lausanne and Lausanne University Hospital, Route de la Corniche 10, CH-1010 Lausanne, Switzerland. E-mail: antje.horsch@ chuv.ch; Tel : +41 795560750

Word count (exclusive of abstract and references): 3495

Acknowledgements: We would like to thank all participants and Vania Sandoz for her help with recruitment. 


\begin{abstract}

\section{Background}

Mental imagery may reflect the present, past or future. Childbirth is often anticipated with joy but also in some cases with fear, which may negatively impact on the childbirth experience. So far, research on birth-related mental imagery in pregnancy is lacking. This study aimed to investigate in detail the phenomenology of spontaneous childbirth-related mental images, and the association between main imagery characteristics (valence, positive/negative percentage ratio, and impact on behaviour and decision-making) and fear of childbirth.
\end{abstract}

\title{
Methods
}

A cross-sectional mixed methods design was employed. Thirty-seven nulliparous, Frenchspeaking women, aged $\geq 18$ years in their third trimester of pregnancy completed self-report questionnaires assessing fear of childbirth, spontaneous use of mental imagery, prenatal depression, trait anxiety, and participated in a mental imagery interview to assess spontaneous childbirth-related mental images. Women with a prenatal diagnosis of malformation were excluded.

\section{Results}

All participants reported having spontaneous mental images of their impending childbirth. The images captured were rich in detail and included a variety of sensory modalities. More positive mental images were associated with less fear of childbirth $(r=-$ 0.533, $p=.008$ ) and women who had a higher proportion of negative mental images had a higher fear of childbirth $(r=0.428, p=.005)$. The impact of the most negative mental images on behaviour and decision-making was positively correlated with fear of childbirth $(r=0.342$, $p=.038)$.

\section{Conclusion}


Results indicate that negative spontaneous imagery around childbirth is associated with fear of childbirth. Intervention techniques could be developed that focus on enhancing positive childbirth-related mental images during pregnancy, counteracting fear of childbirth and fostering a more positive childbirth experience.

Keywords: mental imagery, fear of childbirth, pregnancy, mixed method 


\section{Introduction}

Mental images allow humans to remember, make decisions, or simulate a possible future(Holmes, Crane, Fennell, \& Williams,2007;Pearson, Naselaris, Holmes, \& Kosslyn,2015). In contrast to verbal thoughts, mental images possess multi-modal sensory qualities (i.e., touch, hearing, taste, and smell)(Day,Holmes, \& Hackmann,2004), of which visual is the most common and the most studied modality(Kosslyn, Ganis, \& Thompson,2001). The person's perspective in the mental image can be from one's eyes, from an observer field, or alternate between the two(D'Argembeau, Van der Linden, d'Acremont, \& Mayers,2006). Mental images have a powerful impact on emotion and can be either positive, negative or neutral in valence(Holmes \& Mathews,2010), as brain systems processing emotions can be activated by mental images as well as real-life events(Holmes \& Mathews,2005;Mathews, Ridgeway, \& Holmes,2013).

In patient populations, spontaneous (i.e., not induced) mental images and their links with emotions have been studied in the context of various mental health disorders(Hackmann \& Holmes, 2004). Studies found links between mental images and emotions in social phobia(Hackmann, Clark, \& McManus,2000) and depression(Hales, Deeprose, Goodwin, \& Holmes,2011;Wesslau, Cloos, Hofling, \& Steil,2015) but also in individuals with physical health problems. For example, chronic pain patients who reported pain-related images had higher levels of anxiety and depression(Berna et al.,2011;Gosden, Morris, Ferreira, Grady, \& Gillanders,2014).

Mental images may reflect the present, past or future(Holmes \& Mathews,2010). They can be initiated by sensory cues, thus creating images from episodic memory (bottom-up), which lead to re-experiencing a past event(Holmes \& Mathews,2010). For example, in PTSD, mental images reflect events that happened in the past, whereas mental imagery of chronic pain patients often reflect current sensations(Berna et al.,2011;Gosden et al.,2014). 
Alternatively, mental images can also be voluntary and deliberate (top-down), thus allowing the simulation of a possible future(Pearson et al.,2015). The valence and frequency of positive images as well as the imbalance of negative and positive mental images, are potential maintaining factors in anxiety(Moscovitch, Gavric, Merrifield, Bielak, \& Moscovitch,2011) and depression(Wesslau \& Steil,2014). Depressed individuals appear less able to generate positive mental images about future events than non-depressed individuals(Holmes, Lang, Moulds, \& Steele,2008;Morina, Deeprose, Pusowski, Schmid, \& Holmes,2011). The vividness of suicidal flash-forwards in patients with bipolar disorder is linked with the severity of their suicidal ideation(Holmes et al.,2007), and prospective positive images impact decision-making and goal-directed behaviour(Laing, Morland, \& Fornells-Ambrojo,2015).

Some future events have the particularity that they can be anticipated but stay unpredictable and ambiguous. This is the case with childbirth, an important and stressful life event (Horsch \& Ayers,2016) that is often anticipated with joy but also with anxiety or fear(Geissbuehler \& Eberhard, 2002; Gepshtein,2010), and in some cases with extreme fear(Bhatia \& Jhanjee, 2012), which may negatively impact on the childbirth experience and outcomes(Adams, Eberhard-Gran, \& Eskild,2012). However, birth-related mental imagery in pregnancy remains to be studied, and is of particular interest given their potential of impacting on the emotional wellbeing, decision-making, and behaviour. The first pregnancy is an important transitional period during which a mental reorganization takes place that prepares a woman for her future maternal role(Ammaniti, Tambelli, \& Odorisio,2013). During this time, mental representations of the woman as a future mother and those of her future baby, for example in dreams, are formed(Lara-Carrasco, Simard, Saint-Onge, Lamoureux-Tremblay, \& Nielsen, 2013).

The aim of the current study was to (1) investigate the phenomenology of spontaneous childbirth-related mental images of nulliparous women during their third trimester of 
pregnancy, and to (2) investigate the association between main imagery characteristics (valence, positive/negative percentage ratio, and impact on behaviour and decision-making) and fear of childbirth (FoC). We expected that women with high FoC who see their impending childbirth as a potential threat or danger would not be able to generate strongly positive childbirth-related mental images compared with women with low FoC. Furthermore, we predicted that the impact of birth-related images on behaviour and decision-making would be related to FoC. These questions are important, as they may provide clues for a potential intervention to improve the emotional wellbeing of women during pregnancy and positively influence the childbirth experience and outcomes.

\section{Method}

\section{Procedure}

A cross-sectional mixed methods design including quantitative and qualitative questions was employed. Recruitment took place between August 2014 and September 2016. French-speaking nulliparous women in their third trimester of pregnancy and over 18 years old were eligible to participate. Women who had received a prenatal diagnosis of malformation were excluded, as this was likely to influence the content of their spontaneous mental images. The study received ethical approval from the ethics committee of the Canton Vaud in Switzerland (approval number: 215/14). Flyers were available in the waiting rooms and distributed by obstetric and midwifery staff to pregnant women attending routine appointments at the maternity unit of a Swiss University Hospital. Interested women were invited to contact us and had the opportunity to discuss any questions by telephone before giving their written consent. Questionnaires were completed before the interview (time for completion: approximately $30 \mathrm{~min}$ ), all of which were conducted by the first author. 
A total of 41 pregnant women contacted the research team, 40 were eligible (one woman already had a child), 38 agreed to participate, and 37 finally completed the study (one woman gave birth before the interview).

\section{Measures}

The Childbirth-related Mental Imagery Interview (CMII) was developed based on previous interviews assessing mental images in other populations(Hackmann et al.,2000;Osman, Cooper, Hackmann, \& Veale,2004) and lasted 60-90 minutes. A definition of mental images was given at the beginning of the interview(Day et al.,2004) and an exercise of imagining a lemon was carried out to demonstrate a mental image(Holmes, Lang, et al.,2008; Holmes \& Mathews,2005). The CMII contains three sections assessing the most recent, the most positive and the most negative spontaneous mental images related to impending childbirth. For each of the three identified mental images, participants were asked to describe the content. Then detailed questions concerning different sensory modalities were posed. Participants were then asked about the situational context in which the images appeared, as well as their impact on behaviour and decision-making, and the valence of the image. The point of view (internal/external), the perceived control regarding the image, if the image was voluntary or involuntary produced, and if the trigger was perceived to be internal or external, were assessed.

The Spontaneous Use of Imagery Scale (SUIS)(Reisberg, Pearson, \& Kosslyn,2003) contains 12 -items to assess the everyday use of mental images. Each item is rated on a 5-point Likert-scale. A higher mean-score signifies more important everyday use of mental images. This instrument has good psychometrics qualities(Nelis, Holmes, Griffith, \& Raes,2014; Reisberg et al.,2003). For this study, the English version was translated into French using 
principles of good practice for the translation and cultural adaptation(Wild et al.,2005). The Cronbach's alpha in the present study was $\alpha=.802$

The Edinburgh Postnatal Depression Scale (EPDS)(Cox, Holden, \& Sagovsky,1987) assesses depressive symptoms in the preceding 7 days and has been validated for pregnant women(Bunevicius, Kusminskas, Pop, Pedersen, \& Bunevicius,2009). It contains 10 items rated on a 4-point Likert scale, with the total score ranging from 0 to 30 . A higher score indicates more severe depression. In pregnancy, a score $<10$ indicates no depressive symptoms, 10-12 indicates a suspicion of moderate depression, and $>12$ probable depression(Eberhard-Gran, Tambs, Opjordsmoen, Skrondal, \& Eskild,2004).The French version has good psychometric properties(Guedeney \& Fermanian,1998). The Cronbach’s alpha in this study was $\alpha=.837$

The Trait Anxiety Inventory (STAI-T)(Spielberger, Gorsuch, Lushene, Vagg,\& Jacobs, 1983) has 20-items assessing the natural tendency of being anxious and of evaluating situations as threatening. Each item is rated on a 4-point Likert-scale. The total score ranges from 20 to 80, with a higher score indicating higher anxiety. The French version has good psychometric properties(Bruchon-Schweitzer \& Paulhan,1993). The Cronbach's alpha in this study was $\alpha=.867$

The Wijma Delivery Expectancy Questionnaire (W-DEQ A)(Wijma, Wijma,\& Zar, 1998) assesses FoC in pregnant women. It contains 33 items rated on a 6-point Likert scale. The total score ranges from 0 to 165 , with a higher score indicating higher FoC: low $(<37)$; moderate (37-65) or high (>65)(Zar, Wijma, \& Wijma,2001). This scale has good psychometrics properties(Wijma et al.,1998). The English version was translated into French using principles of good practice for the translation and cultural adaptation(Wild et al.,2005). The Cronbach's alpha in this study was $\alpha=.860$ 
Finally, participants were asked about their age, marital status, and education, as well as obstetric information, such as gestational age, number of fetal ultrasounds so far, preferred/planned mode of delivery, whether they had experienced a perinatal loss or an abortion, or past or present mental health problems.

\section{Data analysis}

Quantitative data were analysed with IBM SPSS statistics 22. Analysis of normality (Kolmogorov-Smirnov Test) and equality of variance (Levene's test for Equality of Variance) was done for each variable. Parametric tests were used when the criteria for such tests were met; otherwise non-parametric tests were performed. Pearson correlations assessed possible associations between characteristics of mental images and FoC scores. A content analysis based on the manifest content of the mental images was performed(Graneheim \& Lundman, 2004).

\section{Results}

\section{Sample}

Thirty-seven pregnant women aged between 24 and 40 years $(M=32.0, S D=3.7)$ participated in the study. Thirty-six (97.3\%) were in a couple relationship, and $29(78.4 \%)$ had a university-level education (Table 1). Ten participants (27.0\%) scored highly and 24 $(64.9 \%)$ moderately for FoC, $6(16.2 \%)$ reached suspicion of moderate depression and 2 (5.4\%) scored for probable depression (Table 2). 


\section{Characteristics of mental images}

All participants used mental images in their routine life, as measured by SUIS. During the CMII, all participants reported having at least one positive mental image about their impending childbirth. When considering all childbirth-related mental images they had had, participants reported that $57 \%$ of these were positive, $20 \%$ negative, and $23 \%$ neutral. A positive percentage ratio corresponding to (positive percentage/(negative percentage + neutral percentage) was calculated with a mean of $2.5(S D=2.6)$, indicating that overall, positive mental images were more frequent that negative and neutral ones.

Positive mental images: The most positive childbirth-related mental images concerned three time periods during childbirth: "labour" (e.g.,baby turns inside the womb in preparation for birth) (14\%), "when the baby is emerging” (e.g.,mother extracts the baby and puts him on her chest) (21\%), and "after the baby is born" (e.g.,first encounter with the baby) (65\%). The first time the positive mental image appeared was related to "healthcare aspects of pregnancy" (e.g.,during ultrasound) for $27 \%$ of the participants, for $23 \%$ it was linked with "non-medical discussions, or images about childbirth" (e.g.,after having watched a video of someone describing their childbirth), for $23 \%$ it happened at the "beginning of the pregnancy or while alone thinking about the childbirth" (e.g., when finding out about pregnancy), and 27\% did not remember when the image appeared for the first time.

When women were asked how often their most positive image occurred, the responses were almost equally distributed from "rarely" through to "every time I think about the childbirth". Half of the triggers of these images were categorized as external (e.g.,during meeting with midwife). Half of the participants experienced the positive image voluntarily and the mean valence of these images was extremely high (91/100). The image had an impact on the behaviour in $67.6 \%$ of cases (e.g.,women felt motivated to engage in more physical activity). No perceived control over the image was felt in $70.3 \%$ of the cases (Table 3 ). 
Regarding the visual characteristics, the index of sharpness was 70.9/100. Most images were three-dimensional $(86.5 \%)$ and the point of view of the image was mainly through one's eyes $(40.5 \%)$. One-third experienced both points of view within the same image (27\%). Most images were in motion (86.5\%) (Table 4) and $43.2 \%$ of the images had a sound component (e.g.,baby's cry) (Table 5).

Nearly half of the participants had a sensation of touch (e.g.,holding the baby) and one-third had a kinaesthetic sensation of feeling their own body moving (e.g, leaning forward to see their baby). Half of the participants reported internal sensations, such as cold, hunger, or pain. One participant reported a sense of taste and $21.6 \%$ of participants experienced a sense of smell linked with the image (e.g.,hospital smell).

Negative mental images: The most negative childbirth-related mental images concerned four themes: "physical problems of the baby" (32\%) (e.g.,umbilical cord is too short and baby cannot breathe), "Labour, pain, and mother's difficulties” (30\%) (e.g., pain, tearing, and blood), "Medical procedure" (22\%) (e.g.,being cut open for cesarean section), "Others" (11\%) (e.g.,placenta taking too long to be expulsed). Two women could not recall any negative mental image. The first time the mental image appeared happened during "nonmedical discussions, or images about childbirth" (e.g.,talking with friends) for $37 \%$ of the participants, for $23 \%$ it was linked with "healthcare aspects of pregnancy" (e.g.,during birth preparation class), for $9 \%$ it was linked with something else, and $31 \%$ did not remember when the image appeared for the first time.

When women were asked how often their most negative image occurred, the responses were mainly "rarely" (45.7\%) and "from time to time" (31.4\%). Triggers of negative mental images were mainly internal (60\%) (e.g., when thinking of the childbirth). Most of the time $(57.1 \%)$ the negative images were experienced involuntary and the mean valence of the images was high (74.4/100) (i.e., very negative). The image had an impact on the behaviour in 
$68.6 \%$ of cases (e.g.,seeking comfort by husband). No perceived control over the image was felt in $82.9 \%$ of the cases (Table 3).

Regarding the visual characteristics, the index of sharpness was 64.3/100. Most images were three-dimensional $(71.4 \%)$, the point of view of the image was mainly through observer perspective (60.0\%), and most images were in motion (54.3\%) (Table 4). Half of the images had a sound component (e.g.,machine sounds) (Table 5).

About a quarter of participants had a sense of touch (e.g.,needle in the back). Onethird had a kinaesthetic sensation of feeling their own body moving (e.g.,reaction of pain). Half of the participants reported internal sensations, such as cold, hunger, or pain but only one participant reported a sense of taste. Finally, three participants experienced a sense of smell linked with the image (e.g.,burned skin).

\section{Correlations between main characteristics of mental images and FoC}

Positive mental images. The positive percentage ratio was negatively correlated with W-DEQ A total-score $(r=-0.428, p=.005)$, i.e., women with a higher proportion of positive mental images had lower FoC. Focusing on the most positive image, the strength of valence of the mental images was negatively correlated with W-DEQ A total score, i.e., the more positive the image, the lower the FoC $(r=-0.533, p=.008)$. However, the impact of the most positive mental image on behaviour and decision-making was not significantly correlated with W-DEQ A total score $(r=-0.105, p=.535)$.

Negative mental images. The negative percentage ratio was positively correlated with W-DEQ A total score $(r=0.428, p=.005)$, i.e., women with a higher proportion of negative mental images had higher FoC. Focusing on the most negative image, the valence of the mental images was not correlated with W-DEQ A total score $(r=0.154, p=.363)$. However, the 
impact on behaviour and decision-making was positively correlated with W-DEQ A total score $(r=0.342, p=.038)$.

\section{Discussion}

The first aim of this study was to investigate in detail the phenomenology of spontaneous childbirth-related mental images. As expected, all participants reported having mental images of their impending childbirth. The mental images captured were rich in detail and contained a variety of different sensory modalities. The second aim was to investigate the association between main imagery characteristics and FoC. Our study is the first to show that more positive mental images were associated with less FoC and that women with a higher proportion of negative mental images had a higher FoC. Furthermore, the impact of the most negative mental images on behaviour and decision-making was positively correlated with FoC.

Our study showed for the first time that in a healthy sample of pregnant women, mental images seemed to have a clear impact on reported behaviour and decision-making, as found in other populations(Holmes, Geddes, Colom, \& Goodwin,2008; Laing et al.,2015). Positive mental images seemed to occur more often than negative mental images. This may be a reflection of the fact that the majority of women in this sample had a planned pregnancy, a favourable socio-demographic and educational background, and low depressive and anxiety symptoms, although $65 \%$ of women reported a moderate and $27 \%$ a high FoC. Compared with a sample of healthy Canadian pregnant women(Hall et al.,2009), our proportion of women reporting a low FoC was lower. However, our sample contained only nulliparous women, which was not the case in the Canadian study. 
The majority of the most positive future mental images focused on the moment when the mother met her baby for the first time after birth, capturing an experience of happiness and bonding with the baby. This positive anticipation of the arrival of the baby may also be a reflection of the fact that all participants had planned pregnancies. The contents of negative mental images were related to a fear of complications, such as instrumental delivery, pain or obstetrical injuries, all of which are commonly observed in pregnant women(Hanna-Leena Melender,2002). The content of these negative images may also be partly explained by the fact that our sample consisted of Research from Japan reported that pregnant women found it particularly helpful if midwives during their preparation for childbirth focussed on the positive aspects of labour and childbirth to enhance the expectation of happiness, positive change, and bonding, and less on medical aspects, anxiety, and fears (Gepshtein,2010). So far, few studies have focused on a positive psychological attitude during pregnancy or ways to mentally simulate and prepare for this experience. Confidence in one's own ability to cope with difficult events during childbirth and the ability to adapt one's behaviour (self-efficacy) are negatively correlated with fear in pregnant women and may reduce the risk of postnatal emotional difficulties(Schwartz et al., 2015). That is why enhancing childbirth self-efficacy expectancy is as important as reducing fears and anxiety about impending labour and childbirth(Lowe, 2000). Reinforcing positive mental images could be an easy tool to enhance childbirth self-efficacy expectancy and to promote well-being after childbirth.

Positive mental images were mainly seen from one's eyes, whereas negative mental images were mainly seen from the observer perspective, although our study was not designed to detect this statistically. However, this may be of interest, as it has been shown that people with social phobia remembered negative social events from an observer perspective to a greater extent than negative non-social events(D'Argembeau et al.,2006). So far, no study compared childbirth-related positive and negative mental images regarding their 
characteristics. Although we did not statistically test this, negative mental images seemed to score lower for many visual characteristics (sharpness, colour, brightness, more often in two dimensions and still) than positive mental images. This may indicate a less important impact of the negative mental images on the emotional well-being of the women in our sample and a more favourable positive bias in this sample(Holmes, Blackwell, Burnett Heyes, Renner, \& Raes,2016). Previous research found that memories for positive events contained more sensory details than memories for negative events(D'Argembeau et al.,2006).

Some participants described that negative mental images were important in order to "test" different possible birth scenarios, whilst at the same time wanting to protect themselves from negative feelings and worries. Negative mental imagery therefore seemed to allow some participants to rehearse less optimal birth scenarios consistent with the idea of mental imagery as a form of mental simulation(Ji, Heyes, MacLeod, \& Holmes,2016). We showed for the first time negative associations between valence of positive mental images and $\mathrm{FoC}$, and ratio of positive/negative images and FoC. As expected, this means that women with high FoC perceive their impending childbirth as a potential threat/danger and have thus difficulties to generate positive mental images. Although this has previously been shown in adults with depression(Holmes, Lang, et al.,2008; Morina et al.,2011), the link with FoC in pregnancy is novel (particularly given that depression scores were low in our sample), and future studies should explore this in more detail.

Interestingly, we also found for the first time that the impact of negative mental images on behaviour and decision-making was correlated with FoC. This means that imagining a possible negative childbirth scenario has more impact on behaviour when it occurs in the context of FoC, possibly because coping is necessary to manage psychological stress(Lazarus,1993). In response to negative mental images, women either applied strategies to deal with their resulting negative emotions, such as seeking comfort and reassurance, or 
strategies to avoid the negative childbirth scenario or to be better prepared should it come true, such as doing exercises to "turn the baby around". These strategies may be classified as emotion-focused or problem-focused coping strategies(Lazarus,1993). Indeed, no coping strategies are needed when positives mental images appear and less efficient coping strategies are sufficient when there is no FoC.

Limitations of our study included the small sample size and low socio-demographic diversity of our sample, with mainly highly educated women living with their partner. This study has clinical implications, such as developing intervention techniques that focus on enhancing positive childbirth-related mental images during pregnancy, thus increasing childbirth self-efficacy expectancy(Schwartz et al.,2015) and improving the childbirth experience. Furthermore, having the opportunity to discuss childbirth-related mental images with staff involved in antenatal care may help women to discuss potential worries and fears and to put strategies and procedures into place that might help improve their well-being during pregnancy and ultimately their childbirth experience.

\section{References}

Adams, S. S., Eberhard-Gran, M., \& Eskild, A. (2012). Fear of childbirth and duration of labour: a study of 2206 women with intended vaginal delivery. BJOG, 119(10), 12381246. doi:10.1111/j.1471-0528.2012.03433.x

Ammaniti, M., Tambelli, R., \& Odorisio, F. (2013). Exploring Maternal Representations During Pregnancy in Normal and At-Risk Samples: The Use of the Interview of Maternal Representations During Pregnancy. Infant mental health journal, 34(1), 1-10.

Berna, C., Vincent, K., Moore, J., Tracey, I., Goodwin, G. M., \& Holmes, E. A. (2011). Presence of Mental Imagery Associated with Chronic Pelvic Pain: A Pilot Study. Pain medicine, 12, 1086-1093.

Bhatia, M. S., \& Jhanjee, A. (2012). Tokophobia: A dread of pregnancy. Indutrial psychiatry journal, 21(2), 158-159. doi:10.4103/0972-6748.119649

Bruchon-Schweitzer, M., \& Paulhan, I. (1993). Manuel du STAI-Y de C.D. Spielberger, adaptation française. Paris: ECPA.

Bunevicius, A., Kusminskas, L., Pop, V. J., Pedersen, C. A., \& Bunevicius, R. (2009). Screening for antenatal depression with the Edinburgh Depression Scale. Journal of 
psychosomatic obstetrics and gynaecology, 30(4), 238-243. doi:10.3109/01674820903230708

Carruthers, H. R., Miller, V., Morris, J., Evans, R., Tarrier, N., \& Whorwell, P. J. (2009). Using art to help understand the imagery of irritable bowel syndrome and its response to hypnotherapy. The International journal of clinical and experimental hypnosis, 57(2), 162-173. doi:10.1080/00207140802665401

Cox, J. L., Holden, J. M., \& Sagovsky, R. (1987). Detection of postnatal depression. Development of the 10-item Edinburgh Postnatal Depression Scale. The British journal of psychiatry: the journal of mental science, 150, 782-786.

D'Argembeau, A., Van der Linden, M., d'Acremont, M., \& Mayers, I. (2006). Phenomenal characteristics of autobiographical memories for social and non-social events in social phobia. Memory, 14(5), 637-647. doi:10.1080/09658210600747183

Day, S. J., Holmes, E. A., \& Hackmann, A. (2004). Occurrence of imagery and its link with early memories in agoraphobia. Memory, 12(4), 416-427. doi:10.1080/09658210444000034

Eberhard-Gran, M., Tambs, K., Opjordsmoen, S., Skrondal, A., \& Eskild, A. (2004). Depression during pregnancy and after delivery: a repeated measurement study. Journal of psychosomatic obstetrics and gynaecology, 25(1), 15-21.

Geissbuehler, V., \& Eberhard, J. (2002). Fear of childbirth during pregnancy: a study of more than 8000 pregnant women. Journal of psychosomatic obstetrics and gynaecology, 23(4), 229-235.

Gepshtein, Y. (2010). Happiness as an outcome of childbirth: the perspective of traditional Japanese midwives and their patients. In A. Makinen \& P. Hàjek (Eds.), Psychology of Happiness (pp. 157-167). New York: Nova Science Publishers Inc.

Gosden, T., Morris, P. G., Ferreira, N. B., Grady, C., \& Gillanders, D. T. (2014). Mental imagery in chronic pain: Prevalence and characteristics. European journal of pain, 18(5), 721-728. doi:10.1002/j.1532-2149.2013.00409.x

Graneheim, U. H., \& Lundman, B. (2004). Qualitative content analysis in nursing research: concepts, procedures and measures to achieve trustworthiness. Nurse Education Today, 24(2), 105-112. doi:10.1016/j.nedt.2003.10.001

Guedeney, N., \& Fermanian, J. (1998). Validation study of the French version of the Edinburgh Postnatal Depression Scale (EPDS): new results about use and psychometric properties. European psychiatry: the journal of the Association of European psychiatry, 13(2), 8389. doi:10.1016/S0924-9338(98)80023-0

Hackmann, A., Clark, D. M., \& McManus, F. (2000). Recurrent images and early memories in social phobia. Behaviour research and therapy, 38, 601-610.

Hackmann, A., \& Holmes, E. A. (2004). Reflecting on imagery: a clinical perspective and overview of the special issue of memory on mental imagery and memory in psychopathology. Memory, 12(4), 389-402. doi:10.1080/09658210444000133

Hales, S. A., Deeprose, C., Goodwin, G. M., \& Holmes, E. A. (2011). Cognitions in bipolar affective disorder and unipolar depression: imagining suicide. Bipolar disorders, 13(78), 651-661. doi:10.1111/j.1399-5618.2011.00954.x

Hall, W. A., Hauck, Y. L., Carty, E. M., Hutton, E. K., Fenwick, J., \& Stoll, K. (2009). Childbirth fear, anxiety, fatigue, and sleep deprivation in pregnant women. Journal of Obstetric, Gynecologic, \& Neonatal Nursing, 38(5), 567-576.

Hanna-Leena Melender, R. (2002). Experiences of fears associated with pregnancy and childbirth: a study of 329 pregnant women. Birth, 29(2), 101-111.

Holmes, E.A., Blackwell, S. E., Burnett Heyes, S., Renner, F., \& Raes, F. (2016). Mental imagery in depression: Phenomenology, potential mechanisms, and treatment implications. Annual review of clinical psychology, 12, 249-280. 
Holmes, E.A., Crane, C., Fennell, M. J., \& Williams, J. M. (2007). Imagery about suicide in depression--"Flash-forwards"? Journal of behavior therapy and experimental psychiatry, 38(4), 423-434. doi:10.1016/j.jbtep.2007.10.004

Holmes, E.A., Geddes, J. R., Colom, F., \& Goodwin, G. M. (2008). Mental imagery as an emotional amplifier: application to bipolar disorder. Behaviour research and therapy, 46(12), 1251-1258. doi:10.1016/j.brat.2008.09.005

Holmes, E.A., Lang, T. J., Moulds, M. L., \& Steele, A. M. (2008). Prospective and positive mental imagery deficits in dysphoria. Behaviour research and therapy, 46(8), 976-981. doi:10.1016/j.brat.2008.04.009

Holmes, E.A. \& Mathews, A. (2005). Mental imagery and emotion: a special relationship? Emotion, 5(4), 489-497. doi:10.1037/1528-3542.5.4.489

Holmes, E.A. \& Mathews, A. (2010). Mental imagery in emotion and emotional disorders. Clinical psychology review, 30(3), 349-362. doi:10.1016/j.cpr.2010.01.001

Horsch, A., \& Ayers, S. (2016). Childbirth and Stress. In G. Fink (Ed.), Stress: Concepts, Cognition, Emotion, and Behaviour (1st ed.): Elsevier.

Ji, J. L., Heyes, S. B., MacLeod, C., \& Holmes, E. A. (2016). Emotional mental imagery as simulation of reality: fear and beyond - a tribute to Peter Lang. Behavior Therapy, 47(5), 702-719.

Kosslyn, S. M., Ganis, G., \& Thompson, W. L. (2001). Neural foundations of imagery. Nature Reviews Neuroscience, 2(9), 635-642.

Laing, J., Morland, T., \& Fornells-Ambrojo, M. (2015). The Phenomenology and Generation of Positive Mental Imagery in Early Psychosis. Clinical psychology \& psychotherapy. doi:10.1002/cpp.1976

Lara-Carrasco, J., Simard, V., Saint-Onge, K., Lamoureux-Tremblay, V., \& Nielsen, T. (2013). Maternal representations in the dreams of pregnant women: a prospective comparative study. Frontiers in psychology, 4, 551. doi:10.3389/fpsyg.2013.00551

Lazarus, R. S. (1993). Coping theory and research: past, present, and future. Psychosomatic medicine, 55(3), 234-247.

Lowe, N. K. (2000). Self-efficacy for labor and childbirth fears in nulliparous pregnant women. Journal of psychosomatic obstetrics and gynaecology, 21(4), 219-224.

Mathews, A., Ridgeway, V., \& Holmes, E.A. (2013). Feels like the real thing: imagery is both more realistic and emotional than verbal thought. Cognition \& emotion, 27(2), 217-229. doi:10.1080/02699931.2012.698252

Morina, N., Deeprose, C., Pusowski, C., Schmid, M., \& Holmes, E.A. (2011). Prospective mental imagery in patients with major depressive disorder or anxiety disorders. Journal of anxiety disorders, 25(8), 1032-1037. doi:10.1016/j.janxdis.2011.06.012

Moscovitch, D. A., Gavric, D. L., Merrifield, C., Bielak, T., \& Moscovitch, M. (2011). Retrieval properties of negative vs. positive mental images and autobiographical memories in social anxiety: outcomes with a new measure. Behaviour research and therapy, 49(8), 505-517. doi:10.1016/j.brat.2011.05.009

Nelis, S., Holmes, E. A., Griffith, J. W., \& Raes, F. (2014). Mental imagery during daily life: Psychometric evaluation of the Spontaneous Use of Imagery Scale (SUIS). Psychologica Belgica, 54(1), 19-32. doi:10.5334/pb.ag

Osman, S., Cooper, M., Hackmann, A., \& Veale, D. (2004). Spontaneously occurring images and early memories in people with body dysmorphic disorder. Memory, 12(4), 428-436. doi:10.1080/09658210444000043

Pearson, J., Naselaris, T., Holmes, E. A., \& Kosslyn, S. M. (2015). Mental Imagery: Functional Mechanisms and Clinical Applications. Trends in cognitive sciences, 19(10), 590-602. doi:http://dx.doi.org/10.1016/j.tics.2015.08.003 
Reisberg, D., Pearson, D. G., \& Kosslyn, S. M. (2003). Intuitions and Introspections about Imagery: The role of imagery experience in shaping an investigator's theoretical views. Applied cognitive psychology, 17, 147-160. doi:10.1002/acp.858

Schwartz, L., Toohill, J., Creedy, D. K., Baird, K., Gamble, J., \& Fenwick, J. (2015). Factors associated with childbirth self-efficacy in Australian childbearing women. BMC Pregnancy Childbirth, 15, 29. doi:10.1186/s12884-015-0465-8

Spielberger, C. D., Gorsuch, R. L., Lushene, R., Vagg, P., \& Jacobs, G. (1983). Manual for the state-trait anxiety inventory (form $Y$ ): self-evaluation questionnaire: Consulting Psychologists Press Palo Alto, CA.

Wesslau, C., Cloos, M., Hofling, V., \& Steil, R. (2015). Visual mental imagery and symptoms of depression - results from a large-scale web-based study. BMC Psychiatry, 15(1), 308. doi:10.1186/s12888-015-0689-1

Wesslau, C., \& Steil, R. (2014). Visual mental imagery in psychopathology--implications for the maintenance and treatment of depression. Clinical psychology review, 34(4), 273281. doi:10.1016/j.cpr.2014.03.001

Wijma, K., Wijma, B., \& Zar, M. (1998). Psychometric aspects of the W-DEQ; a new questionnaire for the measurement of fear of childbirth. Journal of psychosomatic obstetrics and gynaecology, 19(2), 84-97.

Wild, D., Grove, A., Martin, M., Eremenco, S., McElroy, S., Verjee-Lorenz, A., \& Erikson, P. (2005). Principles of Good Practice for the Translation and Cultural Adaptation Process for Patient-Reported Outcomes (PRO) Measures: report of the ISPOR Task Force for Translation and Cultural Adaptation. Value Health, 8(2), 94-104. doi:10.1111/j.15244733.2005.04054.x

Zar, M., Wijma, K., \& Wijma, B. (2001). Pre- and Postpartum Fear of Childbirth in Nulliparous and Parous Women. Scandinavian Journal of Behaviour Therapy, 30(2), 75-84. doi:10.1080/02845710121310 
Table 1: Sample characteristics $(n=37)$

\begin{tabular}{ll}
\hline Demographic variables & M $(S D)$ or $n(\%)$ \\
\hline Age (years ; $M, S D)$ & $32.0(3.7)$ \\
Nationality $(n, \%)$ & $24(64.9 \%)$ \\
Swiss & $11(29.7 \%)$ \\
European & $2(5.4 \%)$ \\
Non-European & \\
Marital status $(n, \%)$ & $36(97.3 \%)$ \\
Couple & $1(2.7 \%)$ \\
Single & \\
Education $(n, \%)$ & 0 \\
Primary school & $1(2.7 \%)$ \\
Middle school & $2(5.4 \%)$ \\
Secondary school / high school & $5(13.5 \%)$ \\
Apprenticeship & $29(78.4 \%)$ \\
University level & \\
\hline
\end{tabular}

\section{Pregnancy variables}

\begin{tabular}{ll}
\hline Gender of the unborn baby $(n, \%)$ & \\
Known & $19(51.3 \%)$ \\
Do not know & $18(48.7 \%)$ \\
Gestational age (weeks) $(M, S D)$ & $33.1(2.5)$ \\
Nb of fetal ultrasound $(M, S D)$ & $5.9(2.5)$ \\
Previous pregnancy loss $(n, \%)$ & \\
No & $28(75.7 \%)$ \\
Yes & $9(24.3 \%)$ \\
\hline
\end{tabular}


Table 2: Mental health characteristics $(n=37)$

\begin{tabular}{lc}
\hline & $M(S D)$ or $n(\%)$ \\
\hline Past trauma Yes $(n, \%)$ & $17(45.9 \%)$ \\
Past trauma impacting actual pregnancy & $7(18.9 \%)$ \\
W-DEQ A total score $(\mathrm{M}, S D)$ & $55.8(15.7)$ \\
W-DEQ A severity $(n, \%)$ & $3(8.1 \%)$ \\
Low & $24(64.9 \%)$ \\
$\quad$ Moderate & $10(27.0 \%)$ \\
$\quad$ High & $5.6(4.3)$ \\
EPDS total score $(M, S D)$ & \\
EPDS severity $(n, \%)$ & $29(78.4 \%)$ \\
$\quad$ No depressive symptoms & $6(16.2 \%)$ \\
Suspicion of moderate depression & $2(5.4 \%)$ \\
Probable depressive disorder & $37.7(7.8)$ \\
STAI - T total score $(M, S D)$ & $3.4(0.6)$ \\
SUIS mean $(M, S D)$ & \\
\hline S $~$ & \\
& \\
&
\end{tabular}


The most positive MI

$n=37$

$1(2.7)$

$9(24.3)$

8 (21.6)

$5(13.5)$

$6(16.2)$

8 (21.6)

Every time I think about the childbirth

Trigger (n, \%)

Internal

$19(51.4)$

$17(45.9)$

$1(2.7)$

Missing

Experience of the image $(n, \%)$

Voluntary

18 (48.6)

$14(40.0)$

Involuntary

18 (48.6)

$1(2.7)$

$20(57.1)$

Missing

Emotion

Valence of the image $(M, S D)$

$90.7(14.2)$

$74.4(22.9)$

Impact on behaviour / decision making $(n, \%)$

Yes

$25(67.6)$

$24(68.6)$

No

$12(32.4)$

$11(31.4)$

Total number of modalities present $(M, S D)$

Perceived control in image $(n, \%)$

Yes

No
$11(29.7)$

$6(17.1)$

$3.0(1.3)$

$26(70.3)$
$29(82.9)$

$\mathrm{MI}=$ Mental Images; $M=$ mean; $S D=$ standard deviation; $n=$ number 
Table 4: Visual characteristics of mental images

The most positive MI The most Negative MI

\begin{tabular}{lcc}
\hline Total number of images $(n, \%)$ & $37(100)$ & $35(100)$ \\
Sharpness $(0-100)(M, S D)$ & $70.9(25.0)$ & $64.3(29.7)$ \\
Colour $(0-100)^{\mathrm{a}}(M, S D)$ & $64.2(23.1)$ & $48.2(29.3)$ \\
Brightness $(0-100)^{\mathrm{a}}(M, S D)$ & $57.2(19.9)$ & $49.5(20.0)$ \\
Dimension $(n, \%)$ & & $9(25.7)$ \\
2D & $4(10.8)$ & $25(71.4)$ \\
3D & $32(86.5)$ & $1(2.9)$ \\
Missing & & $8(22.9)$ \\
Point of view $(n, \%)$ & $15(40.5)$ & $21(60.0)$ \\
Through one's eyes & $12(32.5)$ & $6(17.1)$ \\
Observer perspective & $10(27.0)$ & $16(54.3)$ \\
Both & & \\
Motion & $5(13.5)$ & \\
Still image & & \\
Movie & & \\
\hline
\end{tabular}

$\mathrm{MI}=$ Mental Images; $M=$ mean; $S D=$ standard deviation; $n=$ number

a50=normal, like reality 
Table 5: Examples of sensory modalities present in mental imagery

\begin{tabular}{ll}
\hline Modality & Examples \\
\hline Visual & During caesarean section: Being cut open with a scalpel; my baby is then taken \\
& out. (IM113) \\
Sound & Cry of my baby, sound of the suction machine.(IM129) \\
Be touched & My husband's hands whilst my baby is put on my chest.(IM114) \\
To touch & I touch my baby; he is wet and warm, and I feel his weight on my body. (IM131) \\
Kinaesthetic & Reaction to pain, I twist and turn.(IM115) \\
Organic & My heart beats and my stomach is in knots. (IM126) \\
Taste & I have a sweet, sugary taste. (IM127) \\
Smell & Hospital smell, disinfectant. (IM126)
\end{tabular}

